City University of New York (CUNY)

CUNY Academic Works

\title{
Bioanalysis for Cocaine, Opiates, Methadone and Amphetamines Exposure Detection during Pregnancy
}

\author{
Marta Concheiro \\ CUNY John Jay College \\ Elena Lendoiro \\ Universidad de Santiago de Compostela \\ Ana de Castro \\ Universidad de Santiago de Compostela \\ Eva Gonzalez-Colmenero \\ Complejo Hospitalario Universitario de Vigo \\ Ana Concheiro-Guisan \\ Complejo Hospitalario Universitario de Vigo
}

See next page for additional authors

\section{How does access to this work benefit you? Let us know!}

More information about this work at: https://academicworks.cuny.edu/jj_pubs/278

Discover additional works at: https://academicworks.cuny.edu

This work is made publicly available by the City University of New York (CUNY).

Contact: AcademicWorks@cuny.edu 


\section{Authors}

Marta Concheiro, Elena Lendoiro, Ana de Castro, Eva Gonzalez-Colmenero, Ana Concheiro-Guisan, Patricia Penas-Silva, Manuel Macias-Cortina, Angelines Cruz-Landeira, and Manuel Lopez-Rivadulla 
Publication: Concheiro M., Lendoiro E., de Castro A., Gónzalez-Colmenero E., Concheiro-Guisan A., Peñas-Silva P., Macias-Cortiña M., Cruz-Landeira A., LópezRivadulla M. "Bioanalysis for cocaine, opiates, methadone and amphetamines exposure detection during pregnancy.” Drug Testing and Analysis, 2017; 9(6):898-904.

\section{Bioanalysis for Cocaine, Opiates, Methadone and Amphetamines Exposure Detection during Pregnancy}

Marta Concheiro, $\mathrm{PhD}^{1 *}$, Elena Lendoiro, $\mathrm{PhD}^{2}$, Ana de Castro, $\mathrm{PhD}^{2}$, Eva GónzalezColmenero, $\mathrm{MD}^{3}$, Ana Concheiro-Guisan, $\mathrm{MD}, \mathrm{PhD}^{3}$, Patricia Peñas-Silva, $\mathrm{MD}^{4}$, Manuel Macias-Cortiña, $\mathrm{MD}^{4}$, Angelines Cruz-Landeira, $\mathrm{PhD}^{2}$, Manuel López-Rivadulla, $\mathrm{PhD}^{2}$

${ }^{1}$ John Jay College of Criminal Justice, City University of New York, New York, USA ${ }^{2}$ Sección de Toxicología, Instituto de Ciencias Forenses, Universidad de Santiago de Compostela, Santiago de Compostela, Spain ${ }^{3}$ Sección de Neonatología, Complejo Hospitalario Universitario de Vigo, Vigo, Spain ${ }^{4}$ Sección de Ginecología y Obstetricia, Complejo Hospitalario Universitario de Santiago de Compostela, Santiago de Compostela, Spain

*Corresponding author:

Marta Concheiro-Guisan, Ph.D. Assistant Professor in Toxicology

Department of Sciences

John Jay College of Criminal Justice

City University of New York

524 West 59th Street - Rm 5.66.02

New York, NY 10019

Phone: 212-237-8492

Email: mconcheiro-guisan@jjay.cuny.edu 


\begin{abstract}
Drug exposure during pregnancy constitutes a major legal issue and public health concern. Drug and metabolite determination in biological matrices from mother and newborn is an objective indication of prenatal drug exposure. However, limited data are available regarding the interpretation of these analytical results in terms of window of detection and degree of exposure. We collected paired maternal hair, meconium, placenta and umbilical cord from 727 mother-newborn dyads. We analyzed these specimens by liquid chromatography tandem mass spectrometry for the determination of cocaine, opioids, methadone and amphetamines, and compared the analytical results from the four different matrices. The cases were divided in non-exposure, low and frequent exposure, based on maternal hair concentrations and segmental analysis by trimesters. For cocaine, 64 cases tested positive in hair, 9 in meconium, 6 in placenta and 7 in umbilical cord. In the case of opioids, 14 maternal hair cases were positive, 11 meconium and umbilical cord and 9 placenta samples. For methadone, 11 cases were positive in hair, 9 in meconium and 6 in placenta and umbilical cord. For amphetamines, 18 cases were positive according to maternal hair, but all meconium, placenta and umbilical cord tested negative. Maternal hair was the most sensitive specimen to detect drug exposure during pregnancy. Meconium, placenta and umbilical cord tested positive if hair concentrations showed frequent drug use during the whole pregnancy, especially during the third trimester. Meconium, placenta and umbilical cord also tested positive for morphine and metabolites, if this drug was administered during labor and delivery.
\end{abstract}

Keywords: meconium, umbilical cord, placenta, cocaine, opioids 


\section{Introduction}

The consumption of drugs of abuse during pregnancy not only constitutes a major public health issue, but also an important legal concern. Prenatal exposure to drugs of abuse has been associated with deleterious short- and long-term effects in the exposed children ${ }^{1,2}$. The type of harm depends on the trimester of the pregnancy. Heavy drug use during the first trimester may result in abortions and malformations (teratogenic effects) ${ }^{3,4}$. In the second and third trimesters, the main harmful effects are related to fetal growth and maturation. One of the most deleterious short-term effects is the neonatal abstinence syndrome (NAS) ${ }^{5}$, and among the long-term effects, problems in neurodevelopment (memory, attention, learning skills $)^{6,7}$. Gestational exposure to licit and illicit drugs is considered the single largest preventable cause of in utero developmental compromise of infants in the $\mathrm{USA}^{8}$. Early diagnosis and treatment achieves the best outcomes. Besides the direct harm on the exposed children, the presence of drug use disorders in parents increases the risk of child maltreatment by threefold or more ${ }^{9,10}$.

In the USA and Europe, drug toxicology screening programs for pregnant women and newborns continue to expand. However, evidence-based guidelines, policies for drug screening/confirmation and referrals in this population are missing. The American Congress of Obstetrics and Gynecology (ACOG) recommends universal drug screening vs. risk-based screening, because the later tends to unfairly target low-income women ${ }^{11}$. The treatment for these women and their detection is complicated because of the involvement of the child welfare and legal systems by wide-ranging country statues, some of which are clinical treatment oriented and some of which are punishment oriented $^{8}$. In the USA, the states of Alabama, South Carolina, and Tennessee have moved to criminalize drug use during pregnancy. In Spain, it is under discussion ${ }^{12}$.

Although maternal interview is the most commonly employed method to detect drug exposure during pregnancy, it is often unreliable due to the under-reporting ${ }^{13}$. The determination of drugs and metabolites in biological specimens from the mother (urine, blood/plasma, oral fluid, sweat), from the newborn (urine, meconium and hair) and from the fetal-maternal unit (amniotic fluid, placenta and umbilical cord) offers an objective evidence of this exposure. Previously published reviews discussed the advantages and disadvantages of some of these matrices ${ }^{14-19}$; however, data about the alternative matrices placenta and umbilical cord are scarce ${ }^{18}$. Also the interpretation of the analytical results of the neonatal biological samples in terms of window of detection and degree of exposure is still not well established.

Maternal hair analysis shows the longest window of detection. Taking into account that hair grows at an accepted rate of $1 \mathrm{~cm} / \mathrm{month}^{20}$, segmental hair analysis can describe the drug exposure throughout the whole pregnancy. Other biological specimens from the mother, such as blood, oral fluid and urine, show a much shorter window of detection (blood and oral fluid hours, and urine days). Among the different specimens from the newborn, meconium, the first stool of an infant, is nowadays considered the "gold standard" to reflect drug exposure during the third trimester ${ }^{18}$. However, its expulsion may take up to 5 days after delivery, or it could be passed in utero, making this matrix unavailable for drug testing. Placenta and umbilical cord offer the advantages of being available at birth and in adequate amount for analysis. However, data about drug and metabolite concentrations and window of detection is limited ${ }^{18,21}$. 
We collected and analyzed paired biological samples from 727 mother and newborn dyads, including maternal hair, meconium, placenta and umbilical cord, to study drug exposure to cocaine, opioids, methadone and amphetamines during pregnancy. Maternal hair was employed as reference to establish the timing and the degree of exposure to the drugs of interest. These biological samples (maternal hair, meconium, placenta and umbilical cord) were compared in terms of windows of detection, analyte and metabolite profile and predominant analytes, and concentrations.

\section{Materials and Methods}

\section{Participants}

The participants were pregnant women who delivered at the University Hospitals of Santiago de Compostela and Vigo, Spain, from January 2012 to December 2015. The participants were informed about the study both in writing and orally before the delivery, and they gave written consent. The subjects were not paid for their participation. The study was approved by the Ethics Committee of the University of Santiago de Compostela, Spain. Eight hundred fifty eight pregnant women agreed to participate in the study. All biological specimens (maternal hair, meconium, placenta and umbilical cord) were collected in 727 cases.

\section{Specimen Collection and Storage}

The entire term placenta and umbilical cord specimens were collected at delivery in a polypropylene container and stored at $-20^{\circ} \mathrm{C}$ until analysis. Meconium specimens were collected from newborn diapers up to 3 days after delivery in polypropylene containers and also stored at $-20^{\circ} \mathrm{C}$ until analysis. Maternal hair specimens (a lock of about 100 hairs) were collected after the delivery from the vertex posterior region, as close as possible from the scalp and tied up at the root. These specimens were stored protected from the light at room temperature until analysis.

\section{Specimen Analysis}

All maternal hair specimens and meconium specimens were analyzed for cocaine, opiates, methadone and amphetamines. Umbilical cord and placenta were analyzed if either maternal hair or meconium specimens tested positive for any drug or metabolite.

Maternal hair, whenever possible based on the length and amount of hair available, was segmented by trimesters. Each lock of hair was measured, and divided into 3 segments corresponding to the 3 trimesters: segment 1 ( $2 \mathrm{~cm} \mathrm{long}$ ) from 0 (root) to 2 $\mathrm{cm}$ for the $3^{\text {rd }}$ trimester; segment $2\left(3 \mathrm{~cm}\right.$ long) from 3 to $5 \mathrm{~cm}$ for the $2^{\text {nd }}$ trimester; and segment 3 ( $3 \mathrm{~cm}$ long) from 6 to $8 \mathrm{~cm}$ for the $1^{\text {st }}$ trimester. If the amount of hair was not enough for segmentation, only 1 segment up to $8 \mathrm{~cm}$ long was analyzed (whole pregnancy).

Maternal hair ${ }^{22}$, meconium ${ }^{21}$ and placenta and umbilical $\operatorname{cord}^{23}$ were analyzed by previously published liquid chromatography tandem mass spectrometry (LC-MSMS) methods. Briefly, hair specimens were analyzed for 35 licit and illicit drugs in $50 \mathrm{mg}$ of 
hair, including cocaine, opioids, methadone and amphetamines. Hair decontamination was performed with dichloromethane and incubation in $2 \mathrm{~mL}$ acetonitrile overnight at $50^{\circ} \mathrm{C}$. The extraction procedure consisted in a liquid-liquid extraction (hexane:ethylacetate, 55:45 v/v, at $\mathrm{pH}$ 9), followed by reversed-phase solid phase extraction (Strata-X cartridges, Phenomenex, Torrance, CA). Reversed-phase chromatographic separation was performed in an Atlantis T3 2.1x100 mm $3 \mu \mathrm{m}$ column (Waters, Milford, MA), with acetonitrile and ammonium formate $\mathrm{pH} 3$ as mobile phase and a 32 minute of total run time. The method was linear from $0.5-100$ to 2,000-20,000 $\mathrm{pg} / \mathrm{mg}$, depending on the compound, and the limit of detection (LOD) was 0.5-100 $\mathrm{pg} / \mathrm{mg}$.

Placenta and umbilical cord were analyzed for the determination of opioids (morphine, morphine-3-glucuronide, morphine-6-glucuronide, codeine, 6-acetilmorphine (6 AM)), amphetamines (amphetamine, methamphetamine, 3,4methylenedioxyamphetamine(MDA), 3,4-methylenedioxymethamphetamine (MDMA)), cocaine (cocaine, benzoylecgonine (BE), ecgonine methyl ester (EME), hydroxy-benzoylecgonine (OH-BE)) and methadone (methadone, and 2-ethylidene-1,5dimethyl-3,3-diphenylpyrrolidine (EDDP)). One gram $( \pm 0.02 \mathrm{~g})$ of placenta or umbilical cord was homogenized in $5 \mathrm{~mL}$ of water with the Ultra-Turrax T8 dispenser (IKA, Staufen, Germany). After the addition of $50 \mu \mathrm{L}$ of $10 \%$ formic acid and centrifugation, the supernatants were submitted to cation exchange solid phase extraction (OASIS MCX cartridges, Waters). Chromatographic separation was performed in an Atlantis T3 $2.1 \mathrm{x}$ $100 \mathrm{~mm} 3 \mu \mathrm{m}$ column (Waters), acetonitrile and $0.1 \%$ formic acid as the mobile phase, and 18 minutes of total run time. The linearity ranged from $1-2.5 \mathrm{ng} / \mathrm{g}$ to $100-500 \mathrm{ng} / \mathrm{g}$, and the LOD was $0.5-2.5 \mathrm{ng} / \mathrm{g}$, depending on the compound.

Meconium was analyzed for the same drugs and metabolites as placenta and umbilical cord. In this case, $0.5 \pm 0.01 \mathrm{~g}$ of meconium was pretreated with $2 \mathrm{~mL}$ of methanol $+0.01 \%$ formic acid, and mixed in a rotor for 30 minutes. After centrifugation, the supernatant was evaporated to dryness and reconstituted in $200 \mu \mathrm{L}$ methanol and 2 $\mathrm{mL}$ of $0.1 \%$ formic acid. This solution was submitted to cation exchange solid phase extraction (OASIS MCX cartridges, Waters). Chromatographic separation was performed in an Atlantis T3 $2.1 \times 100 \mathrm{~mm} 3 \mu \mathrm{m}$ column (Waters), acetonitrile and formic acid 0.1\% as mobile phase, and 18 minutes of the total run time. The LOD was $0.5-2.5 \mathrm{ng} / \mathrm{g}$, depending on the compound, and the linearity was from 5 to $500 \mathrm{ng} / \mathrm{g}$. Supplemental Table 1 summarizes the LOD, LOQ and cutoffs for each analyte for each specimen.

\section{Comparison of Hair, Meconium, Placenta and Umbilical Cord}

To compare the different matrices, we considered maternal hair as the reference matrix. We classified the degree of exposure based on hair concentrations in "frequent exposure", "low exposure" and "non-exposure". For "frequent exposure" we used the cutoff values recommended by the Society of Hair Testing (SoHT) for opioids (morphine or $6-\mathrm{AM}$ at $200 \mathrm{pg} / \mathrm{mg}$ ), for cocaine (cocaine at $500 \mathrm{pg} / \mathrm{mg}$ and BE at $50 \mathrm{pg} / \mathrm{mg}$ ), and for amphetamines (amphetamine, methamphetamine, MDA or MDMA at $200 \mathrm{pg} / \mathrm{mg}$ ). In the case of methadone we established the cutoff at $200 \mathrm{pg} / \mathrm{mg}$, similar to opioids. For "low exposure" we employed the method's LOQ for the compounds of interest ( $20 \mathrm{pg} / \mathrm{mg}$ ) up to SoHT cutoff values. "Non-exposure" specimens were the cases where drugs were 
negative. For meconium, placenta and umbilical cord, the specimens were considered positive for any drug if the concentration was above the methods' LOQ (1-5 ng/g).

\section{Results}

\section{Cocaine}

Sixty-two cases were positive for cocaine in hair ( $8.7 \%$ of total samples). Thirty-four specimens out of 62 could be segmented by trimesters, corresponding to the first, second and third trimester, and in 28 cases only one segment $8 \mathrm{~cm}$ long, reflecting the whole pregnancy, was analyzed. The concentrations in the segmented specimens ( $n=34$ cases) were cocaine $20-24,275 \mathrm{pg} / \mathrm{mg}$ ( $\mathrm{n}=76$ segments), BE 20-15,355 pg/mg ( $\mathrm{n}=74$ segments) and cocaethylene $20-281 \mathrm{pg} / \mathrm{mg}$ ( $\mathrm{n}=11$ segments). Eight cases showed at least one of the 3 segments with concentrations above the SoHT cocaine cutoff; 4 cases showed all the three segments above SoHT cutoff, 3 cases showed only the third segment (first trimester) above the cutoff, and one case the second and the third segments (first and second trimester). With regard to the one segment specimens, the concentrations were cocaine $31-22,390 \mathrm{pg} / \mathrm{mg}$ ( $\mathrm{n}=29$ samples), BE 34-23,730 pg/mg ( $\mathrm{n}=29$ samples $)$ and cocaethylene $20-361.5 \mathrm{pg} / \mathrm{mg}(\mathrm{n}=9$ samples $)$. Thirteen samples showed concentrations above the SoHT cocaine cutoff.

Nine meconium specimens were positive for cocaine and metabolites $(1.2 \%$ of total samples). OH-BE was detected in all samples $(\mathrm{n}=9)$ at concentrations $10-321 \mathrm{ng} / \mathrm{g}$. EME (4-517 ng/g), BE (2-428 ng/g) and cocaine (5-111 ng/g) were detected in 8 samples, and cocaethylene $(3-95.3 \mathrm{ng} / \mathrm{g})$ in 3 samples. Placenta and umbilical cord were analyzed for cocaine and metabolites if hair $(n=62)$ or meconium $(n=9)$ were positive. Six placenta specimens were positive for cocaine metabolites ( $0.96 \%$ of total samples). EME was positive in 6 samples (1-7 ng/g), BE in 5 cases (1-24 ng/g) and $\mathrm{OH}-\mathrm{BE}$ in one at $1 \mathrm{ng} / \mathrm{g}$. All placenta samples were negative for cocaine and cocaethylene. Seven umbilical cord samples were positive for cocaine and metabolites. EME was positive in 6 samples (1-5.5 $\mathrm{ng} / \mathrm{g}), \mathrm{BE}$ in 6 samples $(1-39.3 \mathrm{ng} / \mathrm{g})$ and cocaine in 2 cases $(2.4-6.2 \mathrm{ng} / \mathrm{g})$. All umbilical cord samples were negative for $\mathrm{OH}-\mathrm{BE}$ and cocaethylene. These results are summarized in Table 1.

Segmental analysis could be performed in 34 hair samples. If all hair segments were above the SoHT cutoff ( $n=4$ cases), which reflected "frequent exposure" throughout the whole pregnancy, the 3 matrices, meconium, placenta and umbilical cord, were positive for cocaine and metabolites. If one or two hair segments, corresponding with the first and/or second trimesters, were above the SoHT cutoff $(n=4)$, meconium, placenta and umbilical cord tested negative for cocaine and metabolites. In all other cases, if hair concentrations were positive but below SoHT cutoff or negative, all meconium, placenta and umbilical cord were negative (Figure 1).

Twenty-eight hair samples could not be divided in segments, and one $8 \mathrm{~cm}$ long segment was analyzed. Thirteen of those cases showed concentrations above the SoHT cutoff. Among these cases, 5 meconium samples were positive for cocaine and metabolites, 3 umbilical cord and 2 placenta samples. If the $8 \mathrm{~cm}$ long segment concentrations were below SoHT or negative, all meconium, placenta and umbilical cord were negative (Figure 1). 
Comparing meconium, placenta and umbilical cord concentrations and metabolite profile, meconium was the matrix that showed the highest concentrations followed by umbilical cord and placenta. The predominant metabolite in meconium was $\mathrm{OH}-\mathrm{BE}$ and in placenta and in umbilical cord was BE.

\section{Opioids}

Fourteen cases were positive for opioids (morphine, codeine, 6-AM) in hair (1.9\% of total cases). Nine cases could be analyzed in 3 segments, while in 5 cases only one $8 \mathrm{~cm}$ long segment could be analyzed. The concentration ranges in the segmented cases were morphine 30-624 pg/mg ( $\mathrm{n}=10$ segments), codeine $20-59 \mathrm{pg} / \mathrm{mg}$ ( $\mathrm{n}=6$ segments), and 6AM 20-1,258 pg/mg ( $n=10$ segments). Six cases showed at least one segment above the SoHT opioids cutoff; in one case all three segments were above the cutoff, and in 5 cases the second segment that corresponded with the second trimester was above the cutoff. The $8 \mathrm{~cm}$ long hair segments showed morphine at 20-284.4 pg/mg $(\mathrm{n}=4)$, codeine 20 $\mathrm{pg} / \mathrm{mg}(\mathrm{n}=3)$ and 6-AM 28.8-155.5 pg/mg $(\mathrm{n}=4)$. Two of these samples were above the SoHT cutoff.

Eleven meconium samples were positive for opioids. Morphine was detected in all cases $(5-109.2 \mathrm{ng} / \mathrm{g})$, morphine-3-glucuronide in 4 cases $(5.4-53.2 \mathrm{ng} / \mathrm{g})$, and morphine-6-glucuronide in 2 cases (1.6-5 ng/g). 6-AM and codeine were not detected in any sample. Nine placenta samples tested positive for opioids. Morphine and morphine3-glucuronide were positive in all cases (1-4.6 ng/g and 10.2-40 ng/g, respectively) and morphine-6-glucuronide in 3 cases (1.3-8.1 ng/g). Codeine and 6-AM were not detected in any sample. Eleven umbilical cord samples were positive for opioids. Morphine and morphine-3-glucuronide were detected in all the specimens (morphine 1-18.9 ng/g, morphine-3-glucuronide $8.8-95.8 \mathrm{ng} / \mathrm{g}$ ) and morphine-6-glucuronide in 8 cases (2-11.1 $\mathrm{ng} / \mathrm{g}$ ). Codeine and 6-AM were not detected in any of the umbilical cord samples. These results are summarized in Table 2 .

Nine hair samples were analyzed in 3 segments corresponding to the different trimesters during pregnancy. One case showed hair concentrations above the SoHT opioids cutoff for all the segments, and meconium, placenta and umbilical cord were positive. The predominant analyte in meconium was morphine, and in placenta and umbilical cord was morphine-3-glucuronide. In five cases, only the second segment, reflecting the second trimester, was above the SoHT cutoff, and all the 3 matrices were negative. Among the $8 \mathrm{~cm}$ long hair segments, 2 cases showed concentrations above the SoHT cutoff, and meconium, placenta and umbilical cord were negative (Figure 2).

In 10 cases, although maternal hair opioid analysis was negative, meconium, placenta and/or umbilical cord tested positive for morphine and/or its metabolites, morphine 3- and 6-glucuronide. In all these cases morphine was administered to the mother in the hospital during labor and delivery.

\section{Methadone}

Eleven cases out of 727 were positive for methadone in hair (1.5\% of total). Six cases could be submitted for segmental analysis, and 5 were analyzed in one segment of $8 \mathrm{~cm}$. The segmented samples showed methadone from 42.7-14,776.1 pg/mg ( $\mathrm{n}=18$ segments), 
and the one segment samples showed methadone in the range 55.1-3,838 pg/mg $(\mathrm{n}=5)$.

Nine meconium samples were positive for methadone exposure. EDDP was detected in all cases with concentrations from 14.6 to $6,049 \mathrm{ng} / \mathrm{g}$, and methadone in 7 samples with concentrations from 244.5 to $3,926 \mathrm{pg} / \mathrm{mg}$. Placenta and umbilical cord were positive in 6 cases, being methadone and EDDP detected in all samples. For placenta, methadone concentrations ranged from 42.1 to $366.3 \mathrm{ng} / \mathrm{g}$ and EDDP from 5.1 to $1,975 \mathrm{ng} / \mathrm{g}$. In the case of umbilical cord, methadone concentrations were $4.3-763 \mathrm{ng} / \mathrm{g}$ and EDDP 1-143.2 ng/g. Meconium showed higher concentrations compared to placenta and umbilical cord. The predominant analyte in meconium was the metabolite EDDP, but in most placenta and in all umbilical cord samples it was methadone. These results are summarized in Table 3.

Meconium, placenta and umbilical cord tested positive if all the 3 hair segments throughout pregnancy were positive for methadone, regardless if these concentrations were above or below the $200 \mathrm{pg} / \mathrm{mg}$ cutoff (all 3 hair segments concentrations $\geq 42.7$ $\mathrm{pg} / \mathrm{mg}$ ). In the case of one segment samples, if methadone concentrations were above the "200 pg/mg" cutoff $(\mathrm{n}=3)$, all meconium samples were positive, 2 placenta and 2 umbilical cord samples. If methadone hair concentrations were below $200 \mathrm{pg} / \mathrm{mg}(\mathrm{n}=2)$, meconium, placenta and umbilical cord were negative (Figure 3).

\section{Amphetamines}

In the case of the amphetamines, 18 cases were positive in hair ( $2.5 \%$ of total cases). Ten could be analyzed in segments, and 8 cases were analyzed as one $8 \mathrm{~cm}$ segment. In the segmented samples, the analytes detected were amphetamine $(33.4-1,204 \mathrm{pg} / \mathrm{mg}, \mathrm{n}=9$ segments), methamphetamine (24.2-130 pg/mg, $\mathrm{n}=5$ segments), MDA (65.6-189 pg/mg, $\mathrm{n}=3$ segments) and MDMA (39.4-191.3 pg/mg, $\mathrm{n}=6$ segments). The concentrations in the one segment samples were amphetamine (53.2-1,899 $\mathrm{pg} / \mathrm{mg}, \mathrm{n}=6)$, methamphetamine (37.8-137.4 pg/mg, $\mathrm{n}=4)$, MDA (78.3-118.4, $\mathrm{n}=2)$ and MDMA (38-209.8 pg/mg, $\mathrm{n}=5)$.

Among the segmented cases, only in one case one segment corresponding with the first trimester of pregnancy showed amphetamine concentrations above SoHT cutoff. All the meconium, placenta and umbilical cord samples tested negative. Although in the case of one segment hair samples, 3 cases showed amphetamine concentrations above the established cutoff and one MDMA case was above the cutoff, all meconium, placenta and umbilical cord tested negative.

\section{Discussion}

We analyzed biological matrices from 727 mother-newborn dyads for the determination of cocaine, opioids, methadone and amphetamines collected from 2012 to 2015. The goal of the study was to compare maternal hair, meconium, placenta and umbilical cord in terms of windows of detection, predominant analytes and metabolites detected, and concentrations. Maternal hair was considered the reference matrix to establish the drugs consumed, timing and degree of exposure (non-exposure, low or sporadic and frequent), and all the cases were analyzed for the drugs of interest. Also meconium was analyzed in all cases because this is the current "gold standard" matrix to detect in utero drug exposure. We explored placenta and umbilical cord as an alternative to detect drug 
exposure during pregnancy. Placenta and umbilical cord were analyzed if either maternal hair or meconium specimens were positive to any drug $(n=124)$. The authors performed a pilot study in 2011 with 175 cases, which results were previously published ${ }^{21}$. In that study, 21 cases were positive for cocaine (12\%), 2 for opioids $(1.1 \%), 5$ for methadone $(2.9 \%)$ and one for amphetamines. Due to the limited number of positive specimens, the study was underpowered. The present work with a larger cohort (727 mother-newborn dyads) was conducted to establish valid observations.

The analytical determination of drugs and/or metabolites in different biological matrices from the mother and the newborn offers an objective identification of drug exposure during pregnancy. The interpretation of the analytical results in the different biological matrices tries to determine when the exposure happened during the pregnancy (first, second or third trimester), for how long (sporadic or frequent) and what amount of drugs were consumed by the mother. Maternal hair shows the longest window of detection and it has been used to monitor drug exposure during pregnancy ${ }^{19}$. Maternal hair is considered the most sensitive specimens to detect drug consumption during this period $^{18,24}$. In the present study, also maternal hair was the most sensitive biological sample to detect drug use or abuse during the whole pregnancy. In addition, as we showed in this study, hair was useful to differentiate between mother use and drugs administered during labor and delivery (opioids hair test negative vs. opioids positive in meconium, placenta and umbilical cord). Despite its usefulness, maternal hair monitoring is not a direct maker of in utero drug exposure, and in some countries, such as the USA, still is required a newborn specimen as evidence of child abuse ${ }^{25}$.

Meconium has become the "gold standard" for drug exposure detection in newborns. Because its formation starts around the $12^{\text {th }}$ week of gestation and it accumulates until birth, it was considered that it reflected drug exposure during the second and third trimester ${ }^{14,15}$. However, it is known that its formation increases during the last trimester (week $28-40$ ), and about $75 \%$ of meconium is produced during the last 8 weeks of pregnancy ${ }^{26}$. Because of this, meconium results may reflect just the last 2-3 months of pregnancy ${ }^{27}$. Previous studies also showed that not just the timing but also the frequency of drug exposure was critical to be able detect drugs in meconium. A frequent and chronic exposure is necessary to produce meconium positive results ${ }^{21,28}$. Our results are in agreement with these previous studies. Meconium only was positive if a frequent drug abuse was documented by hair analysis during the whole pregnancy for cocaine, opioids and methadone, especially during the third trimester.

Umbilical cord tissue is an emerging specimen of considerable interest. Its collection is easy and noninvasive, and compared to meconium it offers the advantages of abundant amount of specimen and readily available at delivery. However, few studies about umbilical cord fully describing this matrix to detect in utero drug exposure (predominant analytes and metabolites, concentrations and windows of detection) are available ${ }^{18}$. Recently, Marin et $\mathrm{al}^{29}$ developed a screening method of 57 drugs in umbilical cord tissue by liquid-chromatography time-of-flight (TOF) mass spectrometry, and compared paired umbilical cord and meconium samples $(\mathrm{n}=7)$. Conflicting results were obtained, and only 2 cases showed meconium-umbilical cord good matching results. Jones et $\mathrm{al}^{30}$ developed a method for the detection of heroin exposure in umbilical cord. The identification of heroin exposed newborns improved due to the monitoring of meconin, a metabolite of the illicit heroin contaminant noscapine. No comparison with 
other specimens was performed. Our present data show that umbilical cord tissue could be an alternative to meconium; however, more sensitive analytical techniques are required due to the lower concentrations detected in this biological sample. It is important to highlight the differences between the most predominant analyte and/or metabolites between these matrices. In the case of cocaine, the most prevalent and/or abundant compound was $\mathrm{OH}-\mathrm{BE}$ in meconium and $\mathrm{BE}$ in umbilical cord. With regard to the opioids, our results showed that it is critical to monitor morphine-3-glucuronide in the case of umbilical cord. This incorporation of glucuronides in umbilical cord samples has been indicated previously ${ }^{21,31}$. Methadone was the predominant metabolite in umbilical cord, while the EDDP was the target compound in meconium ${ }^{32}$. In the present study, meconium and umbilical cord positive results agreement was $60 \%$ for cocaine, $100 \%$ for opioids and $70 \%$ for methadone.

Several studies have been published about placenta as alternative matrix to detect in utero drug exposure ${ }^{21,33,34}$. Falcon et al ${ }^{34}$ compared maternal hair with placenta and fetal remains from abortions at the $12^{\text {th }}$ week of gestation. In that study hair was more sensitive than placenta to detect cocaine (20\% placenta positive) and opiates (none placenta positive) exposure. Previous comparisons between meconium, umbilical cord tissue and placenta showed that placenta performed similar to umbilical cord and both matrices were less sensitive than meconium for cocaine and opiates ${ }^{21,32,33}$. In the present study a better agreement among meconium and placenta results were observed.

Meconium and placenta positive results agreement was $60 \%$ for cocaine, $81.8 \%$ for opioids, and $70 \%$ methadone. As reported before ${ }^{21,33}$, we found that placenta concentrations were 5 to 10 -fold lower than meconium concentrations, and the predominant compound were different in placenta compared to meconium (Tables 1-3), suggesting a higher accumulation happens in meconium. However, this behavior may be the opposite for other compounds such as caffeine and theobromine ${ }^{35}$ and benzodiazepines ${ }^{29,36}$.

The anatomical/physiological differences of these matrices and the physicochemical properties of the drugs and metabolites may influence the different incorporation of drugs and metabolites in meconium, umbilical cord and placenta. We observed a tendency of higher accumulation of more polar compounds in umbilical cord/placenta and more apolar compounds in meconium for some drug groups, such as opioids. All these information should bear in mind in the development of analytical methods in the different matrices to select the appropriate target compounds and concentration range.

Cocaethylene is a specific metabolite that is formed if cocaine and ethanol are consumed simultaneously. Meconium samples were positive for cocaethylene in 3 cases, where the hair concentration was above $131 \mathrm{pg} / \mathrm{mg}$ in the third trimester (segment 1) or above $180 \mathrm{pg} / \mathrm{mg}$ during the whole pregnancy ( $8 \mathrm{~cm}$ segment). In these cases, placenta and umbilical cord were negative for this metabolite. Other alcohol biomarkers, such as fatty acid ethyl esters and ethyl glucuronide and sulfate, have being detected in meconium ${ }^{37}$; however, umbilical cord and placenta data are scarce ${ }^{38,39}$. Unfortunately, other alcohol biomarkers were not investigated in the present study.

Meconium, umbilical cord and placenta reflected drug exposure during pregnancy, but also it is important to highlight that they may reflect drugs administered during labor and delivery. This fact has been reported previously in meconium and 
umbilical cord ${ }^{29,40}$, but there is no data about placenta. In the present study we detected 10 cases that tested positive for morphine and metabolites in these three alternative matrices, due to the administration of morphine to the mother during labor and delivery. The analysis of maternal hair samples excluded opioids use during pregnancy. Although meconium also has been reported positive if drugs were administered to the newborn ${ }^{40}$, the employment of umbilical cord and placenta would exclude these cases.

A limitation of this study could be that not all placenta and umbilical cord samples were analyzed, and therefore a completely comparison with hair and meconium could not be performed. In order to optimize laboratory resources and to be able to analyze the highest number of cases as possible to obtain significant results $(n=727)$, placenta and umbilical cord samples were analyzed if either hair or meconium were positive to any of the investigated drugs or metabolites $(n=124)$. Following the present approach, we could have missed cases where hair and meconium were negative, and placenta and/or umbilical cord were positive, but based on previous studies ${ }^{21,28}$, this number is probably marginal and it would not affect the obtained results. Another observation of the present study was that higher concentrations were found in meconium compared to placenta and umbilical cord. Even though the employed placenta and umbilical cord cutoffs (1-2.5 ng/g) were lower than meconium cutoffs ( $5 \mathrm{ng} / \mathrm{g})$, the development of more sensitive analytical methods in placenta and umbilical cord could have increased the number of positive cases detected.

\section{Conclusion}

We presented the most comprehensive study to date comparing maternal hair, meconium, placenta and umbilical cord for the detection of drug exposure during pregnancy. Maternal hair is the most sensitive matrix to detect cocaine, opioids, methadone and amphetamines use and/or abuse during the three trimesters. Meconium, placenta and umbilical cord reflect drug exposure if the mother drug use was frequent and during the whole pregnancy, specially the third trimester. Attention should be paid to the drugs administered during labor and delivery, because meconium, placenta and umbilical cord may test positive.

This project was supported by the Ministerio de Sanidad, Plan Nacional Sobre Drogas, Gobierno de España 2011/097. None of the authors have any conflict of interest to disclose. 


\section{References}

1. T. Sithisarn, D.T. Granger, H.S. Bada. Consequences of prenatal substance use. Int. J. Adolesc. Med. Health. 2012, 24, 105.

2. M.W. Varner, R.M. Silver, C.J. Rowland Hogue, M. Willinger, C.B. Parker, V.R. Thorsten, R.L. Goldenberg, G.R. Saade, D.J. Dudley, D.Coustan, B. Stoll, R. Bukowski , M.A. Koch, D. Conway, H. Pinar, U.M. Reddy, Eunice Kennedy Shriver National Institute of Child Health and Human Development Stillbirth Collaborative Research Network. Association between stillbirth and illicit drug use and smoking during pregnancy. Obstet. Gynecol. 2014, 123(1), 113.

3. A.J. Wilcox, C.R. Weinberg, D.D. Baird. Risk factors for early pregnancy loss. Epidemiology. 1990, 1, 382.

4. A. Cruz Landeira, C.A. Bouzas Montero, M. Concheiro Guisán, A. de Castro Ríos, O. Quintela Jorge, A.M. Bermejo Barrera, C. Pereiro Gómez. Drogas y Teratogenia. Adicciones. 2006, 18(1), 1.

5. P. Kocherlakota. Neonatal abstinence syndrome. Pediatrics. 2014, 134, e547 (2014). 6. S.D. Díaz, L.M. Smith, L.L. LaGasse, C. Derauf, E. Newman, R. Shah, A. Arria, M.H. Huestis, S.D. Grotta, L.M. Dansereau, C. Neal, B.M. Lester. Effects of prenatal methamphetamine exposure on behavioral and cognitive findings at 7.5 years of age. $J$. Pediatr. 2014, 164(6), 1333.

7. S. Buckingham-Howes, S.S. Berger, L.A. Scaletti, M.M. Black. Systematic review of prenatal cocaine exposure and adolescent development. Pediatrics, 131(6), e1917.

8. B.M. Lester, J.E. Twomey. Treatment of substance abuse during pregnancy. Womens Health. 2008, 4(1), 67.

9. No safe haven: children of Substance-Abusing Parents. National Center on Addiction and Substance Abuse at Columbia University, NY, USA (1999).

10. M. Chaffin, K. Kelleher, J. Hollenberg. Onset of physical abuse and neglect: psychiatric, substance abuse, and social risk factors from prospective community data. Child Abuse Negl. 1996, 20 (3), 191.

11. L. Newman. As substance abuse rises, hospitals drug test mothers, newborns. Clinical Laboratory News, https://www.aacc.org/publications/cln/articles/2016/march/assubstance-abuse-rises-hospitals-drug-test-mothers-newborns, accessed August $4^{\text {th }} 2016$. 12. C. Manzano, R. Figueras, E. Patris, O. García-Algar. Maltrato prenatal. An. Pediatr. 2016, 84, 242.

13. M. Garg, L. Garrison, L. Leeman, A. Hamidovic, M. Borrego, W.F. Rayburn, L. Bakhireva. Validity of Self-Reported Drug Use Information Among Pregnant Women. Matern. Child Health J. 2016, 20(1), 41.

14. T. Gray, M. Huestis. Bioanalytical procedures for monitoring in utero drug exposure. Anal. Bioanal. Chem. 2007, 388, 1455.

15. J. Lozano, O. García-Algar, O. Vall, de la Torre R., G. Scaravelli, S. Pichini. Biological matrices for the evaluation of in utero exposure to drugs of abuse. Ther. Drug Monit. 2007, 29, 711.

16. E. Gallardo, J.A. Queiroz. The role of alternative specimens in toxicological analysis. Biomed. Chromatogr. 2008, 22, 795.

17. J. Płotka, S. Narkowicz, Ż. Polkowska, M. Biziuk, J. Namieśnik. Effects of addictive substances during pregnancy and infancy and their analysis in biological materials. In: 
Reviews of Environmental Contamination and Toxicology, Volume 227. Whitacre DM (Ed.). Springer International Publishing, Switzerland, 2014, 55.

18. A. Concheiro-Guisan, M. Concheiro. Bioanalysis during pregnancy: recent advances and novel sampling strategies. Bioanalysis. 2014, 6(23), 3133.

19. X. Joya, R. Pacifici, J. Salat-Batle, O. García-Algar, S. Pichini. Maternal and neonatal hair and breast milk in the assessment of perinatal exposure to drugs of abuse.

Bioanalysis. 2015, 7(10), 1273.

20. F. Pragst, M.A. Balikova. State of the art in hair analysis for detection of drug and alcohol abuse. Clin. Chim. Acta. 2006, 370, 17.

21. M. Concheiro, E. González-Colmenero, E. Lendoiro, A. Concheiro-Guisán, A.de

Castro, A. Cruz-Landeira, M. López-Rivadulla. Alternative matrices for cocaine, heroin, and methadone in utero drug exposure detection. Ther. Drug Monit. 2013, 35, 502.

22. E. Lendoiro, O. Quintela, A. de Castro, A. Cruz, M. López-Rivadulla. Target screening and confirmation of 35 licit and illicit drugs and metabolites in hair by LCMSMS. Forensic Sci. Int. 2012, 217, 207.

23. A. de Castro, A. Díaz, B. Piñeiro, E. Lendoiro, A. Cruz, M. López-Rivadulla, M. Concheiro. Simultaneous determination of opiates, methadone, amphetamines, cocaine, and metabolites in human placenta and umbilical cord by LC-MS/MS. Anal. Bioanal. Chem. 2013, 405, 4295.

24. E. Lendoiro, E. González-Colmenero, A. Concheiro-Guisán, A. de Castro, A.CruzLandeira, M. López-Rivadulla, M. Concheiro. Maternal hair analysis for the detection of illicit drugs, medicines, and alcohol exposure during pregnancy. Ther. Drug Monit. 2013, $35,296$.

25. Child Welfare Information Gateway. U.S. Department of Health and Human Services. 2012, www.childwelfare.gov

26. A. Bakdash, P. Burger, T.W. Goecke TW, P.A. Fasching, U. Reulbach, S. Bleich, M. Hastedt, M. Rothe, M.W. Beckmann, F. Pragst, J. Kornhuber. Quantification of fatty acid ethyl esters (FAEE) and ethyl glucuronide (EtG) in meconium from newborns for detection of alcohol abuse in a maternal health evaluation study. Anal. Bioanal. Chem. 2010, 396, 2469.

27. M. Hastedt, F. Krumbiegel, R. Gapert, M. Tsokos, S. Hartwig. Fatty acid ethyl esters (FAEEs) as markers for alcohol in meconium: method validation and implementation of a screening program for prenatal drug exposure. Forensic Sci. Med. Pathol. 2013, 9, 287. 28. X. Joya, E. Marchei, J. Salat-Batle, O. García-Algar, V. Calvaresi, R. Pacifici, S. Pichini. Drugs of abuse in maternal hair and paired neonatal meconium: an objective assessment of foetal exposure to gestational consumption. Drug Test. Anal. 2015, DOI: 10.1022/dta.1921.

29. S.J. Marin, A. Metcalf, A.D. Krasowski, B.S. Linert, C.J. Clark, F.G. Strathmann, G.A. McMillin. Detection of neonatal drug exposure using umbilical cord tissue and liquid chromatography time-of-flight mass spectrometry. Ther. Drug Monit. 2014, 36, 119.

30. J.T. Jones, M. Jones, B. Jones, K. Sulaiman, C. Plate, D. Lewis. Detection of codeine, morphine, 6-monoacetylmorphine, and meconin in human umbilical cord tissue: method validation and evidence of in utero heroin exposure. Ther. Drug Monit. 2015, 37, 45. 
31. M. Concheiro, H.E. Jones, R.E. Johnson, R. Choo, D.M. Shakleya, M.A. Huestis. Umbilical cord monitoring of in utero drug exposure to buprenorphine and correlation with maternal dose and neonatal outcomes. J. Anal. Toxicol. 2010, 34, 498.

32. A. de Castro, H.E. Jones, R.E. Johnson, T.R. Gray, D.M. Shakleya, M.A. Huestis. Methadone, cocaine, opiates, and metabolites disposition in umbilical cord and correlations to maternal methadone dose and neonatal outcomes. Ther. Drug Monit. 2011, 33, 443.

33. A. de Castro, H.E. Jones, R.E. Johnson, T.R. Gray, D.M. Shakleya, M.A. Huestis. Maternal methadone dose, placental methadone concentrations, and neonatal outcomes. Clin. Chem. 2011, 57, 449.

34. M. Falcon, S. Pichini, J. Joya, M. Pujadas, A. Sanchez, O. Vall, O. García Algar, A. Luna, R. de la Torre, M.C. Rotolo, M. Pellegrini. Maternal hair testing for the assessment of fetal exposure to drug of abuse during early pregnancy: comparison with testing in placental and fetal remains. Forensic Sci. Int. 2012, 218, 92.

35. I. Martin, M.A. Lopez-Vilchez, A. Mur, O. García Algar, S. Rossi, E. Marchei, S. Pichini. Neonatal withdrawal syndrome after chronic maternal drinking of mate. Ther. Drug Monit. 2007, 29, 127.

36. O. Garcia-Algar, M.A. Lopez-Vilchez, I. Martin, A. Mur, R. Pacifici, S. Rossi, S. Pichini. Confirmation of gestational exposure to alprazolam by analysis of biological matrices in a newborn with neonatal sepsis. Clin. Toxicol. (Phila). 2007, 45, 295. 37. N. Kummer, W.E.E. Lambert, N. Samyn, C.P. Stove. Alternative sampling strategies for the assessment of alcohol intake of living persons. Clinical Biochem. 2016, doi: 10.1016/j.clinbiochem.2016.05.007.

38. L. Morini, M. Falcón, S. Pichini, O. García-Algar, P. Danesino, A. Groppi, A. Luna. Ethylglucuronide and ethyl-sulfate in placental and fetal tissues by liquid chromatography coupled with tandem mass spectrometry. Anal. Biochem. 2011, 418, 30. 39. J. Jones, M. Jones, C. Plate, D. Lewis. The detection of 1-palmitoyl-2-oleoylsnglycero- 3-phosphoethanol and ethyl glucuronide in human umbilical cord. Am. J. Anal. Chem. 2012, 03, 800.

40. G.A. McMilllin, K.E. Wood, F.G. Strathmann, M.D. Krasowski. Patterns of drugs and drug metabolites observed in meconium; what do they mean? Ther. Drug Monit. 2015, 37(5), 568 . 
Table 1. Quantitative results for cocaine and its metabolites benzoylecgonine (BE), hydroxy-BE (OH-BE), ecgonine methyl esther (EME) and cocaethylene (CE) in meconium ( $n=9$ total positive cases $)$, placenta ( $n=6$ total positive cases) and umbilical cord ( $\mathrm{n}=7$ total positive cases).

\begin{tabular}{|c|c|c|c|c|c|}
\hline Matrix & Cocaine $(\mathrm{ng} / \mathrm{g})$ & BE $(\mathrm{ng} / \mathrm{g})$ & OH-BE $(\mathrm{ng} / \mathrm{g})$ & EME $(\mathrm{ng} / \mathrm{g})$ & CE $(\mathrm{ng} / \mathrm{g})$ \\
\hline Meconium & $\begin{array}{c}5-111 \\
(\mathrm{n}=6)\end{array}$ & $\begin{array}{c}2-428 \\
(\mathrm{n}=9)\end{array}$ & $\begin{array}{c}10-321 \\
(\mathrm{n}=10)\end{array}$ & $\begin{array}{c}4-517 \\
(\mathrm{n}=9)\end{array}$ & $\begin{array}{c}3-95.3 \\
(\mathrm{n}=3)\end{array}$ \\
\hline Placenta & 0 & $\begin{array}{c}1-24 \\
(\mathrm{n}=6)\end{array}$ & $\begin{array}{c}1 \\
(\mathrm{n}=1)\end{array}$ & $\begin{array}{c}1-7 \\
(\mathrm{n}=6)\end{array}$ & 0 \\
\hline $\begin{array}{c}\text { Umbilical } \\
\text { Cord }\end{array}$ & $\begin{array}{c}2.4-6.2 \\
(\mathrm{n}=2)\end{array}$ & $\begin{array}{c}1-39.3 \\
(\mathrm{n}=6)\end{array}$ & 0 & $\begin{array}{c}1-5.5 \\
(\mathrm{n}=6)\end{array}$ & 0 \\
\hline
\end{tabular}

Table 2. Quantitative results for morphine, morphine-3-glucuronide (M-3-Gluc) and morphine-6-glucuronide (M-6-Gluc) in meconium ( $\mathrm{n}=11$ total positive cases), placenta $(\mathrm{n}=9$ total positive cases) and umbilical cord $(\mathrm{n}=11$ total positive cases). 6 monoacetylmorphine (6-AM) and codeine were not detected in any specimen.

\begin{tabular}{|c|c|c|c|}
\hline Matrix & Morphine (ng/g) & M-3-Gluc (ng/g) & M-6-Gluc (ng/g) \\
\hline Meconium & $\begin{array}{c}5-109.2 \\
(\mathrm{n}=11)\end{array}$ & $\begin{array}{c}5.4-53.2 \\
(\mathrm{n}=4)\end{array}$ & $\begin{array}{c}1.6-5 \\
(\mathrm{n}=2)\end{array}$ \\
\hline Placenta & $\begin{array}{c}1-4.6 \\
(\mathrm{n}=9)\end{array}$ & $\begin{array}{c}10.2-40 \\
(\mathrm{n}=9)\end{array}$ & $\begin{array}{c}1.3-8.1 \\
(\mathrm{n}=3)\end{array}$ \\
\hline Umbilical & $1-18.9$ & $\begin{array}{c}8.8-95.8 \\
(\mathrm{n}=11)\end{array}$ & $\begin{array}{c}2-11.1 \\
(\mathrm{n}=8)\end{array}$ \\
\hline
\end{tabular}

Table 3. Quantitative results for methadone and its metabolite 2-ethylidene-1,5-dimethyl3,3-diphenylpyrrolidine (EDDP) in meconium ( $n=9$ total positive cases), placenta ( $n=6$ total positive cases) and umbilical cord ( $n=6$ total positive cases).

\begin{tabular}{|c|c|c|}
\hline Matrix & Methadone $(\mathrm{ng} / \mathrm{g})$ & EDDP $(\mathrm{ng} / \mathrm{g})$ \\
\hline Meconium & $244.5-3,926(\mathrm{n}=7)$ & $14.6-6,049(\mathrm{n}=9)$ \\
\hline Placenta & $42.1-366.3(\mathrm{n}=6)$ & $5.1-1,975(\mathrm{n}=6)$ \\
\hline $\begin{array}{c}\text { Umbilical } \\
\text { Cord }\end{array}$ & $4.3-763(\mathrm{n}=6)$ & $1-143.2(\mathrm{n}=6)$ \\
\hline
\end{tabular}




\section{Figure legends}

Figure 1. Cocaine positive cases in hair segmented by trimesters $(n=34)(A)$ and in hair one $8 \mathrm{~cm}$ long segment $(\mathrm{n}=28)(\mathrm{B})$ above and below the Society of Hair Testing (SoHT) cutoff compared to cocaine positive cases in meconium $(n=9)$, placenta $(n=6)$ and umbilical cord $(n=7)$.

Figure 2. Opioids positive (above and below SoHT cutoff) and negative (below method's limit of quantification) cases in hair segmented by trimesters $(n=9$ positive, $n=9$ negative) (A) and in hair one $8 \mathrm{~cm}$ long segment ( $\mathrm{n}=5$ positive, $\mathrm{n}=1$ negative) (B) compared to opioid positive cases in meconium $(n=11)$, placenta $(n=9)$ and umbilical cord $(n=11)$.

Figure 3. Methadone positive (above and below $200 \mathrm{pg} / \mathrm{mg}$ cutoff) cases in hair segmented by trimesters $(n=6)(A)$ and in hair one $8 \mathrm{~cm}$ long segment $(n=5)(B)$ compared to cocaine positive cases in meconium $(n=9)$, placenta $(n=6)$ and umbilical cord $(n=6)$. 
Supplemental Table 1. Limits of detection (LOD) and limits of quantification (LOQ) for hair, meconium, umbilical cord and placenta in the employed methods ${ }^{21-23}$, and cut-offs established by the Society of Hair Testing (SoHT cutoff) in hair. BE: benzoylecgonine; CE; cocaethylene; OH-BE: hydroxyl-benzoylecgonine; 6-AM: 6acetylmorphine; M-3-G: morphine-3-glucuronide; M-6-G: morphine-6-glucuronide; EDDP: 2-ethylidene-1,5-dimethyl-3,3-diphenylpyrrolidine; A: amphetamine; MA: methamphetamine; MDA: 3,4-methylenedioxyamphetamine; MDMA: 3,4methylenedioxymethamphetamine.

\begin{tabular}{|c|c|c|c|c|c|c|c|c|c|}
\hline \multirow{2}{*}{ Analyte } & \multicolumn{3}{|c|}{$\begin{array}{c}\text { Hair } \\
(\mathrm{pg} / \mathrm{mg})\end{array}$} & \multicolumn{2}{c|}{$\begin{array}{c}\text { Meconium } \\
(\mathrm{ng} / \mathrm{g})\end{array}$} & $\begin{array}{c}\text { Umbilical Cord } \\
(\mathrm{ng} / \mathrm{g})\end{array}$ & \multicolumn{2}{c|}{$\begin{array}{c}\text { Placenta } \\
(\mathrm{ng} / \mathrm{g})\end{array}$} \\
\cline { 2 - 11 } & LOD & LOQ & $\begin{array}{c}\text { SoHT } \\
\text { cutoff }\end{array}$ & LOD & LOQ & LOD & LOQ & LOD & LOQ \\
\hline Cocaine & 2 & 20 & 500 & 0.5 & 5 & 0.5 & 1 & 0.5 & 1 \\
\hline BE & 10 & 20 & 50 & 0.5 & 5 & 0.5 & 1 & 0.5 & 1 \\
\hline CE & 10 & 20 & - & 0.5 & 5 & 0.5 & 1 & 0.5 & 1 \\
\hline OH-BE & - & - & - & 2.5 & 5 & 0.75 & 1 & 0.5 & 1 \\
\hline EME & - & - & - & 0.5 & 5 & 0.5 & 1 & 0.75 & 2.5 \\
\hline Morphine & 5 & 20 & 200 & 2.5 & 5 & 0.75 & 1 & 0.75 & 1 \\
\hline Codeine & 2 & 20 & - & 2.5 & 5 & 1 & 2.5 & 0.75 & 1 \\
\hline 6-AM & 2 & 20 & 200 & 2.5 & 5 & 0.75 & 1 & 0.75 & 1 \\
\hline M-3-G & - & - & - & 2.5 & 5 & 1 & 2.5 & 2.5 & 5 \\
\hline M-6-G & - & - & - & 2.5 & 5 & 1 & 2.5 & 2.5 & 5 \\
\hline Methadone & 2 & 20 & - & 0.5 & 5 & 0.5 & 1 & 0.5 & 1 \\
\hline EDDP & - & - & - & 0.5 & 5 & 0.5 & 1 & 0.5 & 1 \\
\hline A & 2 & 20 & 200 & 2.5 & 5 & 0.75 & 1 & 2.5 & 5 \\
\hline MA & 2 & 20 & 200 & 2.5 & 5 & 0.75 & 1 & 0.5 & 1 \\
\hline MDA & 2 & 20 & 200 & 0.5 & 5 & 0.5 & 1 & 1 & 2.5 \\
\hline MDMA & 2 & 20 & 200 & 0.5 & 5 & 0.5 & 1 & 0.75 & 1 \\
\hline
\end{tabular}


Figure 1.

A

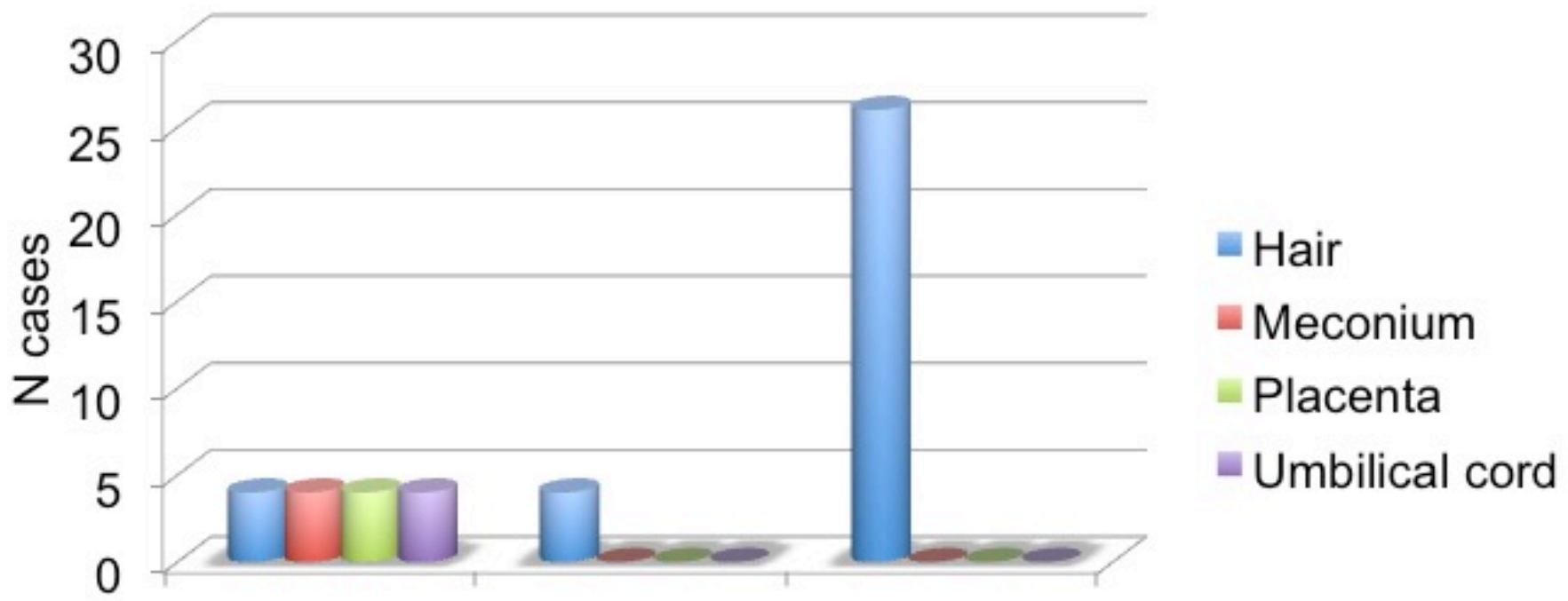

All segments Segment 2-3 Segments $>$ SoHT cutoff $>$ SoHT cutoff $<$ SoHT cutoff

B

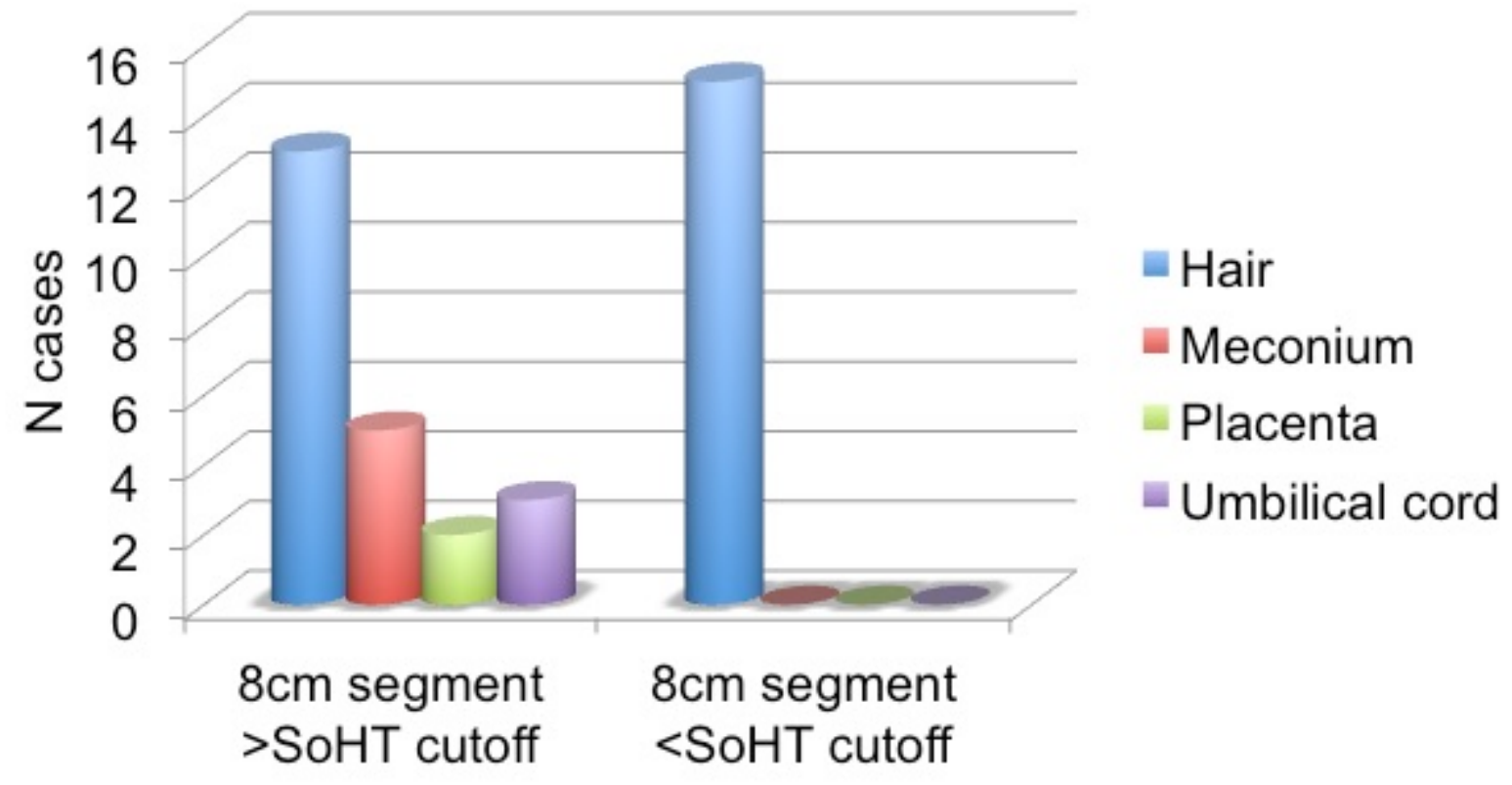


Figure 2.

A

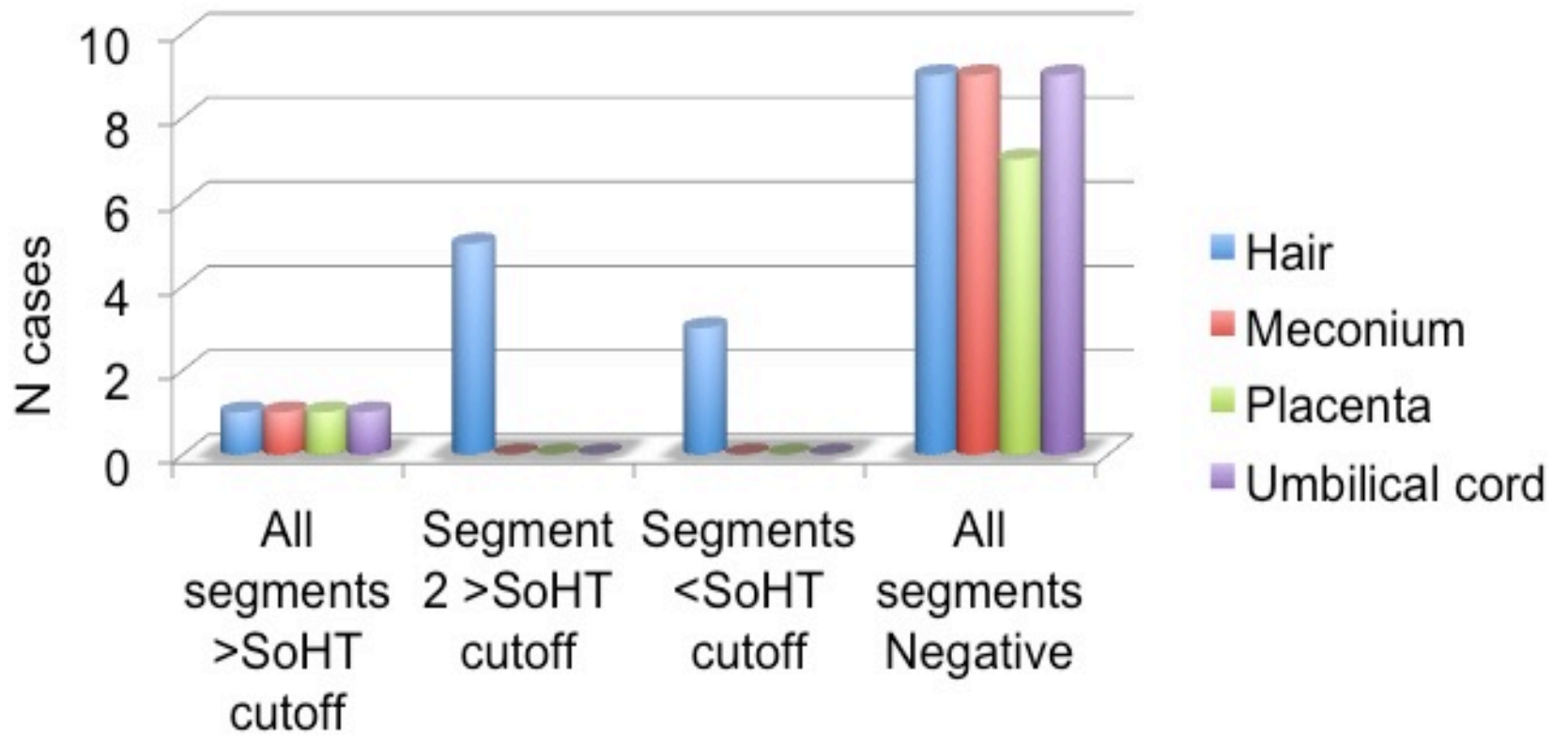

B

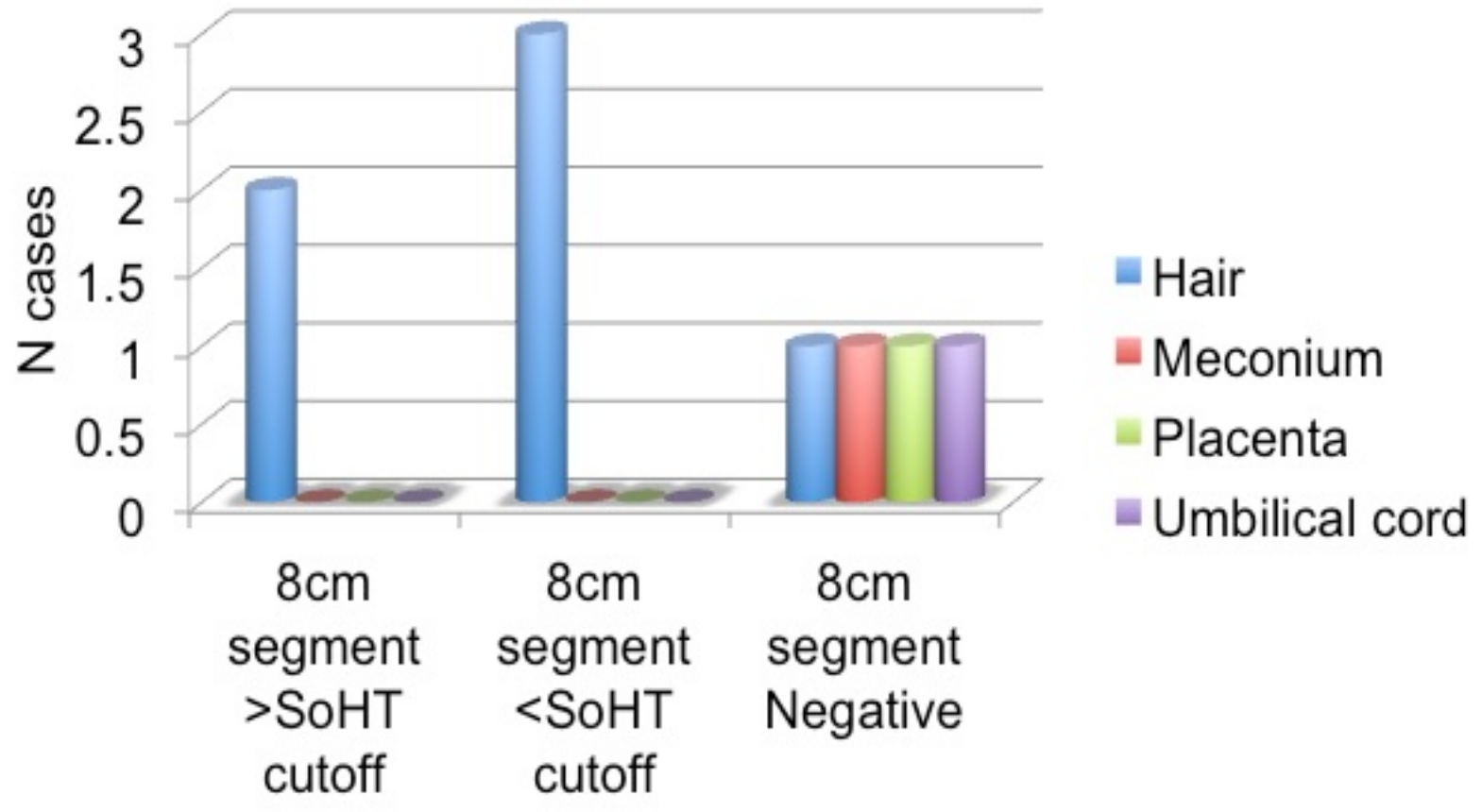


Figure 3.

A

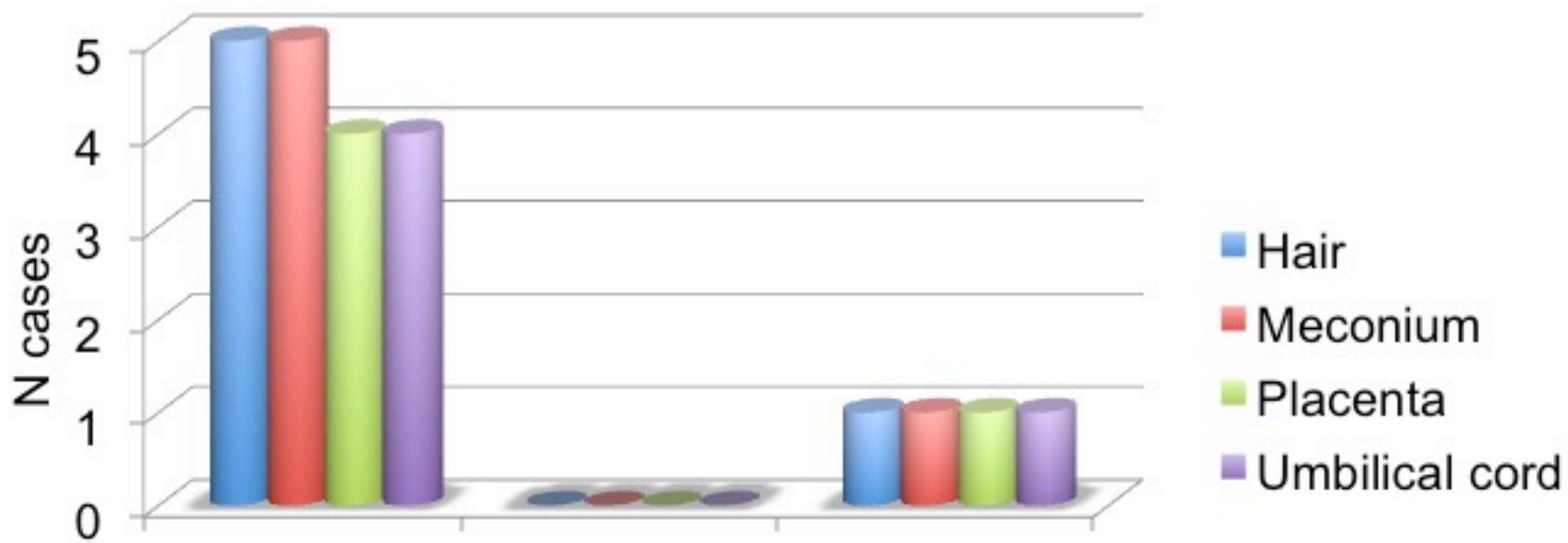

All segments Segment 2-3 Segments

$>200 \mathrm{pg} / \mathrm{mg} \quad>200 \mathrm{pg} / \mathrm{mg} \quad<200 \mathrm{pg} / \mathrm{mg}$ cutoff cutoff cutoff

B

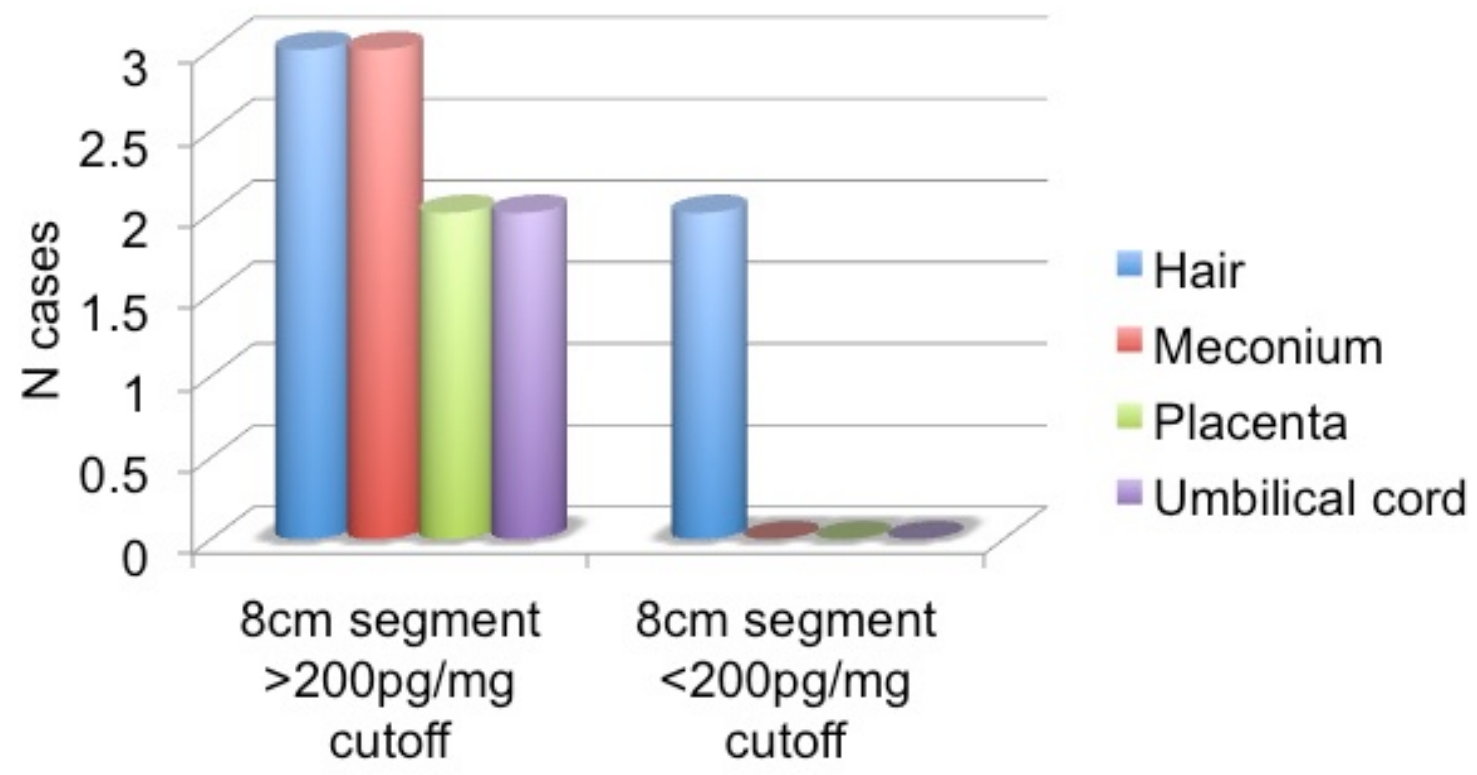

